\title{
Objetos de aprendizaje en la edu- cación virtual: una aproximación en bibliotecología
}

\author{
Roberto Garduño Vera *
}

Artículo recibido:

7 de octubre de 2005.

Artículo aceptado:

21 de noviembre de 2005.

\section{RESUMEN}

En los inicios del siglo XXI la enseñanza de las disciplinas en todos sus niveles y modalidades ha sido afectada por los progresos derivados de la investigación científica y tecnológica. La innovación en tecnología, la privatización y comercialización del conocimiento y la demanda social creciente de propuestas educativas, han ocasionado que las universidades incidan en programas de desarrollo sustentable relacionado con la prestación de servicios educativos. Así, la educación virtual utiliza la información, el conocimiento y los medios para propiciar diálogos didácticos mediados por el proceso de comunicación entre los actores de la formación virtual. En la actualidad el objeto de aprendizaje se sitúa como fenómeno de investigación emergente para las disciplinas debido a la prospectiva que se espera del propio objeto en la educación del presente

* Centro Universitario de Investigaciones Bibliotecológicas de la UNAM, México. garduno@servidor.unam.mx

INVESTIGACIÓN BiBLIOTECOLÓGICA, Vol. 20, Núm. 41, julio/diciembre, 2006, México, ISSN: 0187-358X. pp. 161-194 
siglo. Por lo anterior, se reflexiona aquél a partir de los siguientes asuntos: lo virtual en la formación, la generación de contenido para la educación virtual, la tendencia emergente en el desarrollo de objetos de aprendizaje para la educación en línea, los objetos de aprendizaje y psicopedagogía, los estándares educativos; la investigación en proceso relacionada con objetos de aprendizaje, y las perspectivas de los objetos de aprendizaje en la enseñanza de la disciplina bibliotecológica.

Palabras clave: Formación virtual; Objetos de aprendizaje; Estándares educativos; Educación virtual en bibliotecología; Bibliotecología y objetos de aprendizaje.

\section{ABSTRACT}

Learning objects in virtual education: a library science approach

Roberto Garduño Vera

In these opening years of the new century, teaching in practically all disciplines, at every level and modality has been affected by progress made in scientific and technological research. However, technological innovation, privatization and commercialization of knowledge plus a growing social demand for educational proposals, have led universities to include curricula related with the sustainable development of educational services. Since virtual education uses information, knowledge and media to propitiate didactic dialog by mediating the communication process between the actors involved in virtual education, today the learning object is an emergent research phenomenon in all teaching, and awaits further development. Therefore, this research-in-process-paper deals with learning objects and their perspective for the teaching of library science, and reflects upon the notion of "the virtual" in information, as well as on the generation of content for virtual education, the emergence of learning objects for on-line education, learning objects themselves, psycho-pedagogy and educational standards.

Keywords: Virtual education; Learning objects; Educational standards; Virtual education in library science; Learning objects in library science. 


\section{INTRODUCCIÓN}

En los inicios del siglo XXI, la "educación virtual" se ha posicionado como modalidad alternativa debido, entre otros aspectos, a los avances psicopedagógicos y a la constante innovación tecnológica. Asimismo se ha dado un incremento exponencial de propuestas educativas en línea debido a la influencia ejercida por la globalización y al aumento en el uso de tecnologías de información y comunicación para prestar servicios educativos. Por ello la enseñanza virtual y el desarrollo de "objetos de aprendizaje" $(O A)^{2}$ representan fenómenos de investigación permanente pues son escasas las investigaciones sólidas sobre este asunto, situación que convierte a dichos fenómenos en objetos de estudio necesario en toda área disciplinar.

El aprendizaje por medios digitales se caracteriza por la convergencia de métodos, tecnologías, aplicaciones y servicios orientados a sustentar y facilitar el aprendizaje vía Internet. ${ }^{3}$ Para ello, la formación en línea considera como fundamentales los siguientes aspectos: teorías del aprendizaje, desarrollo de habilidades en el manejo de plataformas tecnológicas; desarrollo de materiales didácticos; desarrollo de objetos de aprendizaje; manejo de parámetros para la evaluación de software educativo orientado al desarrollo de contenido y su distribución vía redes de teleproceso, y planeación de servicios de información documental acordes con la propuesta educativa en línea.

La elaboración de objetos de aprendizaje como apoyo a la educación virtual llama cada vez más la atención de instituciones educativas y de empresas de distinta naturaleza debido a los aspectos mencionados, y también porque

1 Educación virtual: método de enseñanza no presencial basado en las nuevas tecnologías de la información que utiliza [...] como herramienta fundamental el soporte informático, sin prescindir ni atenuar la relación profesor-alumno, pues la comunicación se mantiene y fomenta mediante la Red, en Enciclopedia de pedagogía. España: Espasa, 2002. p. 1039. E-learnig (Aprendizaje electrónico), "[...] el desarrollo de contenidos a través de cualquier medio electrónico, incluyendo Internet, Intranet, extranet, satélites, cintas de audio y video, televisión interactiva y CD-ROM” en URDAN, T. y C. Weggan. Citados por Carlos Marcelo, et al., Formando teleformadores: diseño y desarrollo de un curso online utilizando WebcT. [en línea] <http://s.es/idea/mie/pub/marcelo/Formando\%20Teleformadores.pdf>

[consultada:09/08/05]. Por lo anterior, en este documento los términos mencionados se utilizan indistintamente por ser de mayor interés los más utilizados a nivel mundial.

2 En este trabajo se entiende por objeto de aprendizaje[OA] la unidad de contenido reutilizable por los actores del proceso de aprendizaje que cuentan con facilidades tecnológicas para generar nuevas versiones a partir del objeto de aprendizaje original. También se reconoce la siguiente definición: objeto de aprendizaje, “[...] unidad básica de contenido educativo, que aporta la base para una aplicación generalizada de las nuevas tecnologías de la comunicación y la informática en los modelos pedagógicos tradicionales, así como para la generación de nuevos modelos, más avanzados y mejor adaptados al mundo actual",en Prototipo de patrimonio público de recursos educativos basados en una red institucional y un repositorio distribuido de objetos de aprendizaje. Participantes: Ma. Elena Chan Núñez [y otros] p.12.

3 Alfonso Cornella. "E-Learning: de la formación de los empleados al conocimiento en toda la cadena de valor". en El Profesional de la Información, Vol. 11, Núm. 1, enero-febrero 2002. p. 65. 
pretenden en el corto plazo una baja inversión derivada de la reutilización de tales objetos. Lo anterior presupone incidir en el costo-beneficio que presumiblemente disminuirá la formación de distintos sectores sociales. También es evidente que la educación en línea tiene como intención penetrar en el mercado de la educación en todos sus niveles, y es esto lo que también suscita la reflexión sobre las posibles repercusiones en la educación del presente siglo.

\section{LO VIRTUAL EN LA FORMACIÓN}

En la actualidad es común hablar de educación en línea, educación vía Internet, educación virtual, aprendizaje virtual, entornos virtuales de aprendizaje, etcétera. Sin embargo, conviene en principio preguntar ¿cómo se entiende la virtualidad en este contexto?. Se ha dicho que lo virtual es aquello que está implícito, lo que es de facto. Como término se ha señalado que lo virtual [está] frecuentemente en oposición a efectivo o real, que tiene existencia aparente y no real. ${ }^{4}$ Asimismo se ha dicho que es lo efectivo, aparente, irreal. Que existe en esencia o en sus efectos, aunque no en forma real y verdadera. ${ }^{5}$ A mayor abundamiento, Maestre Yenes señala que lo virtual es: la forma de funcionar basada en las tecnologías de la información y de las comunicaciones en la que se simula el mundo real dando una serie de prestaciones y funcionalidades que permiten en gran medida obtener los mismos servicios y prestaciones que se obtendrían en aquel utilizando las posibilidades que proporciona Internet. ${ }^{6}$

Con base en las ideas precedentes se puede señalar que lo virtual en la educación es la acción que produce aprendizajes en forma no presencial, situación que conlleva a la simulación y a lo simbólico.

Cabe advertir que en estos tiempos la dimensión simbólica está sobredimensionada, en particular desde que los medios masivos de comunicación comienzan a ocupar un lugar destacado en la sociedad y elaboran discursos que explican los hechos, interpretan situaciones y acciones de los seres humanos. ${ }^{7}$

Así, la educación virtual pretende incidir en el uso creciente de Tecnologías de Información y Comunicación (TIC), y motivar el interés de los tutores al ofrecer modelos novedosos de gestión educativa centrados en el aprendizaje

4 Diccionario de la Lengua española, p. 2095

5 Diccionario Enciclopédico de Términos Técnicos, p. 1709

6 Pedro Maestre Yenes. Diccionario de gestión del conocimiento e informática. Madrid: Fundación DINTEL, 2000. p. 240. Tecnología y Comunicación Educativa 1999, Vol. 13, no. 29, p.75 
de los alumnos, lo cual implica fomentar el estudio independiente y el estudio en colaboración; la interacción académica entre tutor-alumno, alumno-tutor; el desarrollo de habilidades cognoscitivas en los estudiantes y el fomento de su capacidad de análisis, de síntesis y de formulación de juicios valorativos. En consecuencia, se requiere incidir en aprendizajes, diseñar estrategias de aprendizaje individual y en equipo que fomente el análisis crítico y la reflexión como bases fundamentales del trabajo en colaboración. En este sentido, las asesorías personalizadas o colectivas requieren de materiales de instrucción, selección de contenidos, lecturas complementarias y fomento del aprendizaje cooperativo mediante la asignación de proyectos o casos de estudio que generen discusiones en equipos, ya sea en forma presencial o en línea. En este contexto, los objetos de aprendizaje podrán ser de mucha utilidad para apoyar aprendizajes a distancia y recrear conocimiento.

Se debe cuidar que los actores del aprendizaje comprendan cabalmente que a través de los $\mathrm{OA}$ es factible formalizar o complementar contenidos de estudio, reciclar el conocimiento relacionado con el aprendizaje para sustentar la generación de nuevo conocimiento y compartir tales conocimientos con alumnos y tutores en distintos niveles geográficos. Este propósito revalora el hecho de que cada estudiante es considerado como el eje del proceso educativo, un gestor de su propio crecimiento intelectual y profesional, y un organizador de tiempos y espacios para estudiar contenidos, lo cual implica oportunidades para ser creativo, reflexivo y analítico. En este sentido, el uso de objetos de aprendizaje puede incidir en que los alumnos en escenarios virtuales fomenten sus habilidades de investigación y adquieran una mayor actitud crítica para seleccionar y asimilar nuevos conocimientos.

Asimismo los objetos de aprendizaje en escenarios virtuales están acelerando la generación de comunidades virtuales que, en los inicios del siglo XXI fracturan fronteras nacionales e internacionales, desbordan contextos institucionales y culturales y evidencian cambios en las formas de comunicarse a través de redes académicas. Cabe preguntar,

¿cuál es el entorno social en el que surge y se afianza el concepto de virtualidad y de objeto de aprendizaje? En principio, [...] se trata de un entorno que va mucho más allá de las posibilidades creadas por la tecnología. O dicho en otros términos, la tecnología [por sí misma] no lo explica. ${ }^{8}$

En este sentido, se puede señalar que la comunidad virtual se hace realidad si existen afinidades temáticas, académicas o intereses investigativos 
comunes, aspectos que pueden dar por resultado la generación y uso de objetos de aprendizaje en escenarios de interacciones sociales y telemáticas. Una comunidad virtual es el núcleo de unión y de interacción a través de temas o asuntos de interés para esa comunidad la cual realiza intercambios de conocimiento a través de red. ${ }^{9}$

Así, lo virtual conlleva la conectividad y a la interactividad, lo cual requiere la unión de distintas tecnologías de red, fenómeno al que se le ha denominado convergencia tecnológica debido a que posibilita la confluencia de diversas tecnologías. Así, la interactividad tiene sentido cuando los sujetos del acto educativo se benefician de ella a través de los flujos de información y conocimiento que se transmiten vía Internet. La transmisión de datos repercute necesariamente en la formación, en la construcción del conocimiento y en lo laboral. Por tanto el escenario virtual incorpora expresiones como navegación, ciberespacio, cibernauta.

Con los nuevos medios de comunicación y su manejo del tiempo-espacio, hemos transitado del medio impreso a la navegación basada en el hipertexto, y del material didáctico impreso y digital al objeto de aprendizaje, nociones que nos exigen contar con conocimientos actuales y nuevas destrezas para poder incidir en aprendizajes virtuales. Nos encontramos ante un escenario novedoso para la educación virtual en el que se destacan las siguientes dimensiones:

- La convergencia de tecnologías, modelos educativos y modelos de comunicación.

- Las relaciones entre la institución, el tutor, el alumno, el material de instrucción y los objetos de aprendizaje proponen cambios significativos frente a la virtualidad.

- Los contenidos de apoyo al proceso de enseñanza-aprendizaje experimentan cambios sustantivos cuando se les aplican las teorías del aprendizaje, la digitalización y el uso de hipermedia en red. Los grupos interdisciplinarios cobran entonces especial importancia para asegurar un adecuado aprovechamiento de los recursos didácticos, los conocimientos y las infraestructuras tecnológicas.

- La recuperación, vía Internet, de la información de apoyo a los aprendizajes, les ha mostrado a los actores del proceso educativo la inestabilidad de la misma y la dificultad para su cotejo en relación con la veracidad y la autenticidad.

- Las necesidades del mercado de trabajo y de los egresados que buscan incorporarse a él, han hecho que las instituciones educativas vean en 
la educación virtual, una estupenda oportunidad para ayudar a resolver estos problemas. Pocos dudan de ello, sin embargo, es conveniente tener en mente que se trata de un desafío que exige asumir compromisos de investigación, estudio y reflexión. Todo ello dirigido a buscar propuestas novedosas y de amplio alcance para el mejor aprovechamiento de la virtualidad en los aprendizajes.

En este entorno, la información y el conocimiento constituyen los elementos sustantivos a partir de los cuales los sujetos del acto educativo participan en procesos de cohesión, globalización, informatización, educación y generación de conocimiento. Así, en los inicios del siglo XXI el uso de tecnologías en propuestas educativas virtuales, potencia la generación de servicios educativos en forma global. Sin embargo, el camino que exige recorrer el mundo tecnológico es largo e incluye diversas problemáticas, sobre todo para aquellos países donde la cultura informática es apenas introductoria, son utilizados de manera restringida los sistemas de información apoyados en tecnologías, los modelos educativos evidencian graves atrasos, y la investigación teórica y tecnológica sobre OA y sus repercusiones es hasta el momento muy escasa.

\section{DesarRollo de CONTENido PARA LA EDUCACión VIRTUAL}

Históricamente la formación a distancia ha mostrado que los materiales didácticos representan uno de los elementos necesarios en la educación de este tipo, debido a que son el enlace de mayor importancia para la comunicación educativa entre quien enseña y quien aprende. Así, el desarrollo de materiales les exige a los autores de contenido asumir posturas teóricas como principio elaborador. Comprender lo que implica educar vía Internet ha sido un requisito indispensable para desarrollar contenidos que cumplan con los requerimientos de la comunicación vía redes de teleproceso, la interacción, la navegación y el diálogo académico remoto entre los actores del aprendizaje.

La tecnología de información y comunicación ha enriquecido las formas de llevar a cabo dichas tareas a través de la convergencia tecnológica de las telecomunicaciones y la informática cuya función es incidir en acciones relacionadas con el desarrollo de software educativo y los sistemas basados en: multimedios, hipertexto e hipermedia con el fin de enriquecer las formas de realizar los aprendizajes a distancia. El uso intensivo de dichas tecnologías incide en los objetivos y los temas de estudio, por lo que la identificación y el tratamiento de los mensajes académicos representan tareas de mucho valor, 
pues se requiere discriminarlos y estructurarlos tomando en cuenta las características particulares de los medios portadores que se pretenda utilizar.

Asimismo el empleo de modelos dirigidos al desarrollo de materiales didácticos presupone que se acudirá al conocimiento y la aplicación de un conjunto de principios normativos, derivados de las teorías del aprendizaje, con los cuales se pretende hacer más eficiente el proceso de elaboración de contenidos. Una característica relevante respecto a los materiales de instrucción que se emplean en la educación virtual es su alto grado de estructuración pedagógica debido a que su finalidad consiste en reforzar los aprendizajes. Por ello, la exploración de un conocimiento más significativo implicaría tomar en consideración que los contenidos didácticos deben tener un ordenamiento lógico, y facilitar la búsqueda de información adicional por parte del alumno proporcionándole bibliografía complementaria.

Lo anterior tiene sentido porque la estructuración pedagógica de los materiales es uno de los requerimientos de la comunicación didáctica a distancia. Lo cual indica que se debe eliminar cualquier tipo de ambigüedad tanto en la estructura como en los contenidos. Por lo tanto se debe procurar hacer llegar al estudiante un discurso académico accesible a su aprendizaje, que lo incite a la reflexión y a la búsqueda de más información sobre el tema de estudio, lo cual resulta un reto para todo autor de contenido. En este sentido el aprendizaje es productivo cuando el alumno es capaz de crear ideas, desarrollar y resolver problemas, y adquirir habilidades que lo hagan útil a la sociedad y en el grupo profesional al que pertenece.

Asimismo los alumnos de programas educativos a distancia exigen, por su condición de adultos, contenidos de aprendizaje que proporcionen no sólo la explicación de fenómenos sino también su posible solución, aplicación y vinculación con los problemas que enfrentan cuando realizan una actividad laboral o cuando tienen problemas propios de su vida cotidiana. Por lo tanto este tipo de alumnos se somete principalmente a dos tipos de procesos educativos: a) el informativo, que consiste en el cúmulo de conocimientos identificados a través de la actividad relacionada con la organización curricular, y b) el formativo, a través del cual el sujeto realiza la aplicación del conocimiento adquirido en la solución de problemas específicos.

En consecuencia el desarrollo de contenidos didácticos debe considerar posturas pedagógicas como la epistemológica, que atañe a la construcción de conocimiento y que conduce a un requerimiento de articulación teórica relacionada con la propuesta educativa en la que se asume un sentido de totalidad relacional, y en la que los objetos de conocimiento no están predeterminados de antemano. La postura teórica asume dos vertientes principales en cuanto a la concepción del aprendizaje: la constructivista y la histórico- 
cultural. En ambas hay en el fondo una postura epistemológica abierta y organicista. De ahí devienen conceptos como el de la problematización y la noción de integridad de las actividades y productos que se espera se construyan a través del desarrollo de las unidades didácticas. ${ }^{10}$

Por tanto el papel del autor de contenido es determinante porque es él quien debe socializar los contenidos y comunicarle la información pertinente al aprendiz. Así, la función de la información es fungir como base de conocimiento para lograr que los estudiantes lleguen a construir estructuras de pensamiento y a solucionar problemas.

Algunas tareas académicas de importancia que realiza el autor de contenidos para la educación virtual podrían ser las siguientes:

1. Seleccionar la información relevante para el fenómeno de estudio que se pretenda abordar.

2. Determinar formas de procesamiento de tal información, como resúmenes, ensayos, etcétera.

3. Identificar casos de estudio con base en los cuales el alumno pueda encontrar formas de relacionarse con diversos fenómenos de aprendizaje.

4. Presentar opciones para el manejo y el análisis de contenidos orientados a producir conocimiento significativo en los estudiantes.

5. Proponer lecturas complementarias que garanticen que los alumnos profundizarán en los temas desarrollados por los contenidos fundamentales de los materiales didácticos.

Con relación a los aspectos precedentes, la teoría relacionada con el desarrollo de materiales didácticos indica que es conveniente considerar básicos los siguientes elementos: el análisis de los objetivos generales y específicos de la propuesta educativa que se haga (considerando la vinculación temática que puedan tener las partes que estructuren el plan de estudios), más los requisitos de ingreso y egreso del programa, y evidenciar luego el conocimiento que el sujeto logró asimilar a través de la evaluación.

Los aspectos mencionados pueden corroborar el grado de aprendizaje obtenido; mostrar si las habilidades programadas fueron alcanzadas, y si la pertinencia de los contenidos y de las actividades de aprendizaje fueron las adecuadas. La evaluación puede tener mayor sentido al considerar de manera puntual el perfil del egresado, lo cual determina las habilidades que se espera aprendan los estudiantes a distancia a través de los contenidos, actividades de aprendizaje, fuentes de información y productos elaborados por ellos mismos. 
En propuestas educativas a distancia, las actividades mencionadas tienen como apoyo estratégico los materiales didácticos, los cuales suelen desarrollarse utilizando una selección y compilación de lecturas de distintas fuentes documentales, o libros y guías de aprendizaje elaborados ex profeso por especialistas de la disciplina involucrada. La antología agrupa documentos selectos y representativos para estudiar un campo temático específico y su elaboración exige analizar y seleccionar diversos autores y documentos para ayudar a los alumnos a incidir en diversas posturas sobre objetos de estudio determinados. Dichas actividades las realizan especialistas de la disciplina que hace la propuesta educativa, e idealmente se recomienda la conformación de un grupo interdisciplinario o multidisciplinario con la intención de que éste garantice la relevancia de los contenidos, las actividades de aprendizaje y los parámetros de evaluación que conduzcan al alumno a distancia a la práctica del estudio independiente.

Parece que, para diseñar materiales de instrucción, desarrollar actividades de aprendizaje y seleccionar lecturas complementarias, los autores de contenido tienden a apoyarse en la concepción constructivista del aprendizaje y, en consecuencia, emprender una actividad de reconstrucción y reestructuración. Es decir, el nuevo conocimiento se construye a partir del conocimiento que ya tenía el sujeto antes de enfrentar la propuesta educativa específica. En consecuencia, es el alumno quien construye su propio conocimiento a través de su participación en actividades planificadas y sistematizadas, orientadas a propiciar en él reflexiones que lo orienten hacia la construcción de su conocimiento tomando como base principal los materiales de instrucción, las lecturas complementarias y las actividades de aprendizaje individuales y en colaboración.

Así, partiendo de uno de los postulados del constructivismo relacionado con la estructura cognoscitiva del alumno, dicha teoría asume que éste cuenta con una serie de antecedentes y conocimientos previos, un vocabulario y un marco de referencia personal, lo que puede indicar aspectos relacionados con su madurez intelectual. Por lo tanto este aspecto es de sumo valor para cualquier autor de contenidos orientados a la educación virtual debido a que el contenido es la unión entre las palabras y la realidad, por lo que su desarrollo representa tareas complejas que exigen que se estructuren los conocimientos que le den coherencia al proceso de enseñanza-aprendizaje en forma mediatizada.

Con base en lo expuesto más arriba, se percibe que la elaboración de contenido didáctico conlleva un seguimiento metodológico estricto. En todo caso, su calidad y exactitud son determinantes para el éxito de la propuesta educativa virtual que se quiera y en consecuencia se justifica la insistencia 
de diversos autores respecto a la conformación de grupos interdisciplinarios para realizar y evaluar esta actividad.

En los inicios de este siglo XXI se advierte que las redes de teleproceso han revolucionado las maneras de acceder, consultar, navegar y utilizar información de diversas fuentes, cada vez más autores de contenido y alumnos tienen libre acceso a documentos digitales disponibles vía Internet. Así, en la actualidad, las tecnologías de información y comunicación eliminan la distancia y el tiempo para recuperar información de circulación libre. Sin embargo, los actores de los procesos educativos virtuales, deberán tener presente que la información disponible en la www puede ser gratuita y remunerada. La remunerada es, por lo general, la que produce la investigación y en consecuencia, ofrece calidad de contenido, cuyo control se hace a través de software que funge como interfaz para su almacenamiento y recuperación en línea. A este tipo de información se le ha vinculado con el comercio electrónico que consiste en la contratación de servicios de información vía red, lo cual permite la recuperación de documentos digitales mediante una remuneración económica que libera la obtención del documento específico. Por lo que toca a la información gratuita se mantiene una postura de desconfianza que inhibe su utilización en el desarrollo de contenidos.

Se puede señalar que las tecnologías de información y comunicación, ofrecen diversas posibilidades para el diseño de modelos educativos y de materiales didácticos con fines de docencia e investigación. Esto pone de manifiesto la incorporación de Tecnologías de la Información y Comunicación (TIC) en la educación virtual y requiere de una adecuación teórica dirigida principalmente al desarrollo de conceptos, y de una definición de estructuras y normas para construir materiales didácticos y objetos de aprendizaje que garanticen la adquisición de conocimiento significativo por parte del alumno. Dichos propósitos se deben considerar en relación con la construcción de modelos integrales en línea, en tanto dispongan de bases de conocimiento flexibles y que muestren el uso pertinente de la teoría que subyace en la educación virtual.

En este contexto, las aulas virtuales contemplan posibilidades tecnológicas para incorporar material didáctico que puede contener texto, gráficos, imágenes y sonido. Así, la comunicación en línea puede enriquecer los procesos educativos de los sujetos del aprendizaje. Asimismo el ideal tecnológico de lograr que la estructura de la web semántica pueda conseguir que las páginas web dejen de ser cadenas de caracteres para las computadoras y se conviertan en textos provistos de semántica, traería consigo nuevas posibilidades para el desarrollo de material didáctico y de objetos de aprendizaje.

El uso creciente de tecnologías en la educación virtual y la innovación constante de las mismas ha hecho más complejo el desarrollo de contenidos 
educativos debido a que su generación debe contemplar el escenario de la revolución tecnológica que ha transformado diversas tareas de las instituciones educativas y en general de toda la sociedad. Así, algunas dimensiones de la educación en línea vinculadas con los objetos de aprendizaje se refieren

[...] al papel de factorías de contenidos en la industria del e-Aprendizaje, diseño y desarrollo de contenidos, tendencias e innovaciones en los contenidos de e-Learnig [...] y fuentes de contenido para el diseño de propuestas de aprendizaje virtuales a la medida. ${ }^{11}$

Por ello, la formación del docente y del autor de contenido debe atender en forma constante las nuevas propuestas generadas por la innovación tecnológica como son los objetos de aprendizaje y los estándares educativos.

\section{Tendencia emergente en el DesarRollo De ObJetos DE APRENDIZAJE PARA LA EDUCACIÓN VIRTUAL}

Los orígenes de la educación en línea y de los objetos de aprendizaje se sitúan en las tecnologías de información y comunicación, y su principal objetivo ha sido la formación de grupos a distancia en distintos niveles educativos. En este sentido, el Learning Management System (LMS) para servidores de Internet-Intranet se propone, entre otras tareas, administrar contenidos para el aprendizaje en línea. Este software representa una tendencia novedosa en el mercado de la educación en línea debido a que los LMS permiten crear pequeñas unidades de contenido educativo llamadas [objetos de aprendizaje] que representan ahorros en tiempo y costos asociados con el desarrollo de contenidos. $^{12}$

La educación virtual se propone avanzar en los próximos años hacia el desarrollo de contenidos que se apoyan en el uso creciente de tecnologías de vanguardia orientadas hacia la interacción académica entre los actores del aprendizaje y hacia la utilización de diversos canales de comunicación que aseguren el fomento del estudio independiente y el aprendizaje en colaboración en escenarios virtuales. Con relación a lo anterior, Loyo ha señalado que

11 Cf. "Contenidos e-learnig", en e-learnig América Latina. La Revista Digital de e-learnig en América Latina, Año1, número 8, noviembre de 2004. [en línea] http://www.elearnigamericalatina.com/edicion/noviembre/index.php [consultada: 03/11/05] Para una mayor información al respecto, también se puede consultar: http://www.elearningamericalatina.com/encuestas/latinoamerica_4.php 
... con la utilización de agentes cooperativos implantados en computadoras, multimedia y utilizando sistemas de enseñanza asistida por computadora, se incrementará la participación interactiva y la interacción directa de los actores del proceso de enseñanza-aprendizaje. ${ }^{13}$

En este contexto, los objetos de aprendizaje, según Cornella, se proponen que:

1. Los cursos monolíticos de larga duración, serán sustituidos por pastillas de conocimiento que respondan a las necesidades de los usuarios. [...] y habrá que construir los contenidos desde el punto de vista de RLO (Reusable Learning Objects), pequeñas experiencias independientes de aprendizaje que contengan un objetivo, una actividad de aprendizaje y una forma de evaluación.

2. Los momentos de aprendizaje podrán realizarse mediante contenidos en una amplia gama de formatos [multimedia], esta nueva visión sobre la formación residirá en facilitarles a los usuarios la identificación de sus objetivos de aprendizaje, así como la navegación por los materiales disponibles.

3. La elaboración de los contenidos no se realizará de manera centralizada sino que cualquier persona podrá estructurar sus conocimientos en un curso, mediante herramientas simples, en forma de plantilla. Cualquiera tendrá entre sus funciones principales aprender y también enseñar con una orientación pedagógica. ${ }^{14}$

En este siglo XXI, el desarrollo de objetos de aprendizaje se perfila como una de las tareas fundamentales de la formación en línea, por lo que definir e identificar el tratamiento de los mensajes en el contenido, representa tareas de mucho valor porque se requiere que sean discriminados y estructurados de tal manera que puedan integrarse a los medios idóneos portadores de contenido. Las tareas requeridas en el diseño y desarrollo de objetos de aprendizaje exige que se tomen en cuenta: los objetivos del curso, las actividades de aprendizaje, los medios de comunicación, las posibilidades de su reutilización por alumnos y docentes, y los parámetros de evaluación de los estudiantes. Asimismo el empleo de modelos dirigidos al desarrollo de objetos de aprendizaje presupone acudir al conocimiento de un conjunto de principios teóricos del aprendizaje con los cuales se pretende hacer más eficiente el proceso de elaboración y uso de dichos objetos.

13 C. Loyo Varela, y V.G. Sánchez. "La telemática y la educación a distancia [en línea]”, en Soluciones Avanzadas, ago. 1995, vol. 4, no. 24 $<$ http://www.lania.mx/nivel2/divulgacion.html>

14 Alfonso Cornella, "E-Learning: de la formación de los empleados al conocimiento en toda la cadena de valor", en El Profesional de la Información, Vol. 11, Núm. 1, enero-febrero 2002. p. 68 
En este sentido la búsqueda de conocimiento significativo en el aprendizaje virtual les indicaría a los autores de contenido que deben considerar que el desarrollo de objetos de aprendizaje tiene como antecedente la riqueza teórica y aplicada de los materiales didácticos utilizados en diversas propuestas educativas a distancia a lo largo del siglo pasado. Por lo tanto, el desarrollo de objetos de esa naturaleza debe por lo menos tener presente el objetivo de la propuesta educativa, el ordenamiento lógico del contenido y los parámetros de evaluación, y contemplar ligas a objetos de aprendizaje que enriquezcan o complementen los contenidos de estudio. Así se entiende que el alumno tendrá capacidad para crear ideas, reflexionar, resolver problemas y generar habilidades que lo hagan útil para la sociedad y la disciplina a la que pertenece. Igualmente el autor de objetos de aprendizaje deberá identificar los medios digitales idóneos para socializar los contenidos, y comunicar la información que sea pertinente para el aprendizaje con el propósito de que los estudiantes a distancia puedan construir estructuras de pensamiento y resolver problemas. Estos propósitos exigen que se tomen en consideración aspectos teóricos relacionados con los aprendizajes.

\section{OBjETOS DE APRENDIZAJE Y PSICOPEDAGOGÍA}

A lo largo del siglo XX se realizaron diversas investigaciones que incluían distintas perspectivas psicopedagógicas en las que predominaba un enfoque: el de las teorías del procesamiento de la información donde se estudia la inteligencia humana desde una perspectiva funcional, mediante estrategias que utilizan los sujetos para resolver problemas. ${ }^{15}$

Asimismo se tiene en mente que un modelo psicopedagógico puede sustentar diversos indicadores relacionados con la educación en línea debido a que dicho modelo tiene como propósitos incidir, entre otras variables, en los criterios básicos de la instrucción relacionados con el diseño, el desarrollo, la producción y la evaluación de objetos de aprendizaje y de los alumnos en línea, debido a que el sustento principal de un modelo de esta naturaleza se apoya en la psicología cognitiva, cuyo fin es promover aprendizajes autónomos y autorregulados por parte de los alumnos a distancia. ${ }^{16}$

15 Cristina Laorden, García Elena y Sánchez Salvador. "Integrando descripciones de habilidades cognitivas en los metadatos de los objetos de aprendizaje estandarizados", en [en línea] http://spedece.uah.es/papers/Laorden_Final.pdf [consultada: 04/02/05]

16 Rina María Romero Martínez y Garduño Vera Roberto, [y otros]. "Modelo psicopedagógico para el diseño y la evaluación de materiales didácticos en la Educación a Distancia”, en Encuentro Internacional de Educación Superior UNAM, Virtual Educa 2005, del 20 al 24 de Junio de 2005, Palacio de Minería, Ciudad de México. [México: CuAEd, unam. 2005, Memorias en CD-ROM] 
En este contexto, la propuesta educativa se debe concebir a partir del fomento de una nueva cultura del aprendizaje, en donde las funciones de los agentes del proceso educativo asuman actitudes específicas y desarrollen habilidades innovadoras orientadas al aprendizaje significativo, las cuales pueden ser promovidas e inducidas por los recursos docentes, tecnológicos, informativos y por los objetos de aprendizaje. ${ }^{17}$

La elaboración de objetos de aprendizaje puede caracterizarse atendiendo al sustento teórico que se asuma; sin embargo los criterios teóricos que se adopten deben contemplar que el desarrollo de objetos de aprendizaje sea flexible en cuanto a la inclusión, actualización y reutilización de contenidos multimedia para garantizar su valor en el proceso de la formación en línea. No obstante, para que un objeto de aprendizaje pueda ser fácilmente reutilizado conviene tomar en consideración diversos estándares tecnológicos con el propósito de que su flujo en línea sea fácil y transparente para el usuario.

\section{ESTÁNDARES EDUCATIVOS EMERGENTES}

Los estándares educativos orientados a la educación en línea, tienen como propósito proponer un conjunto de elementos tecnológicos que armonicen plataformas y objetos de aprendizaje con el propósito de facilitar su desarrollo, el intercambio de contenidos de aprendizaje y su reutilización. Por lo tanto, algunos propósitos de dichos estándares están dirigidos a los siguientes aspectos:

- Durabilidad. La tecnología desarrollada con base en estándares debe prever la obsolescencia de los contenidos de aprendizaje.

- Interoperabilidad. El intercambio de contenidos debe contemplar una amplia variedad de LMS.

- Accesibilidad. El monitoreo académico de los alumnos debe ser permanente.

- Reusabilidad. El mayor valor de los cursos y de los objetos de aprendizaje reside en que puedan ser reutilizados con diferentes herramientas y en distintas plataformas. ${ }^{18}$

Con relación a dichos asuntos, Castellanos ha señalado que en el eAprendizaje, los metadatos describen e identifican los contenidos educativos

17 Ibidem, p.35

18 Daniel Romero, [y otros]; Barale, Juan Pablo; Rinaldi, Carlos Manuel. Gateway para el reciclaje de sistemas e-learning que no cumplen con SORM. En Primer Congreso Virtual Latinoamericano de Educación a Distancia. 23 de marzo al 4 de abril de 2004.

http://www.ateneonline.net/datos/65_03_Romero_Daniel.pdf [Consultada 10-05-2004] 
para que puedan ser encontrados, ensamblados y enviados. El contenido se divide en piezas pequeñas de información llamadas objetos de aprendizaje los cuales pueden ser reutilizados, y adaptados a los perfiles específicos de los alumnos y a los objetivos del aprendizaje. ${ }^{19}$

Las características de mayor relevancia de estos estándares son: que los O.A. se pueden representar en unidades de contenido digital; que refuerzan conceptos, principios o procedimientos; que son durablesy se proponen evitar contenidos obsoletos; que son Inter-operables en cuanto a que se contemplan facilidades para su intercambio a través de LMS; que pueden monitorear el desempeño de alumnos en forma permanente, y que pueden reutilizarse con el apoyo de diferentes herramientas y plataformas, lo cual indica que deben ser flexibles y adaptables al desarrollo de distintas versiones a partir del original. En cuanto a la estructura básica del contenido de estos objetos, se espera que mínimamente contengan: objetivo, contenido propiamente dicho y parámetros de evaluación. Al mismo tiempo es conveniente que el contenido de los objetos de aprendizaje se sustente en teorías pedagógicas como la teoría del procesamiento de la información, la psicopedagogía, el constructivismo, etcétera. En cuanto a medios portadores del objeto de aprendizaje se identifican, entre otros, los audiovisuales, los digitales y los multimedia.

Cabe destacar que en la actualidad los estándares de mayor uso son los siguientes: el IEEE Standard for Learning Object Metadata (IEE1484.12), que contiene especificaciones para generar objetos de aprendizaje utilizando metadatos; el IEEE Draft Standard for XML Binding For Learnig Object Metadata, que contempla directrices para el marcado de contenido en lenguaje XML; el Learning Resources Meta-data Specifications (LMS) que está orientado a generar recursos de aprendizaje normalizados; el Advanced Distributed Learning (ADL) que se generó para el desarrollo de software orientado a OA; el Instructorial Management System Global Learning Consortium (IMS) que se refiere a normas que orientan el desarrollo de plataformas virtuales; el Entreprise Specification (IMS), que se utiliza para la gestión de cursos vía Internet, y el Question \&Test Specification (IMS), que consiste en un módulo para evaluar el aprendizaje.

El Learning Management System (LMS) contempla las especificaciones tecnológicas orientadas hacia la plataforma para servidores Internet e Intranet; el Learning Content Management Systems (LCMS) se encarga de generar el repositorio de objetos de aprendizaje, las herramientas para el desarrollo de OA,

19 Carlos Alberto Castellanos Coutiño, Panorama general de los sistemas de educación a distancia. Ponencia en el Primer Congreso Virtual Latinoamericano de Educación a Distancia: LatinEduca2004.com 
las herramientas de publicación, las herramientas de colaboración para generar OA, la interfaz dinámica para la entrega de OA y los elementos para monitorear los actores del aprendizaje; el Sharable Content Object Reference Model (SCORM) contiene especificaciones para el desarrollo de software, el empaquetado y la entrega de objetos de aprendizaje; el Advanced Distributed Learning (ADL) incluye normas para la publicación de contenidos derivados de OA.

Se puede advertir que en el conjunto de estándares mencionados con anterioridad es factible identificar los que están orientados a definir unidades de aprendizaje y aquellos que apoyan la sistematización de repositorios en red. Respecto a la definición de unidades de aprendizaje se tiende a utilizar las especificaciones y recomendaciones del Institucional Management System (IMS) debido a su especialización y por ser uno de los estándares de uso generalizado. El IMS contempla una serie de propuestas y caracterizaciones de implantación suficientemente extensas como por ejemplo la que se incluye como parte del modelo SCORM. ${ }^{20}$ Con relación a los estándares orientados a la construcción de repositorios en red, aún no están suficientemente desarrollados por lo que es necesario definir los elementos estructurales de repositorios distribuidos en red, la lógica del repositorio en cuanto a su arquitectura interna y las funciones de implantación.

La definición de un estándar de interoperatividad debe permitir la interconexión de repositorios distribuidos a partir del estándar metadatos para objetos de aprendizaje, el Núcleo de Dublín o MARC 21, aspecto que hasta nuestros días se encuentra en etapa de investigación y experimentación. La teoría y la escasa experiencia que se tiene al respecto ha mostrado que los estándares educativos orientados al desarrollo de objetos de aprendizaje requiere de especificaciones más abiertas y flexibles para incorporar metadatos y establecer principios para la construcción de una taxonomía relacionada con los OA a fin de sustentar principios teóricos y tecnológicos para su desarrollo. Al mismo tiempo, se hace visible el requerimiento de incorporar propuestas bibliotecológicas en materia de organización documental a partir de la construcción de bibliotecas digitales de objetos de aprendizaje y sistemas de metadatos.

Lo anterior, incide en la teoría que subyace en los sistemas de metadatos, la cual indica que deben tomarse en cuenta las características y la relación que puede haber entre los elementos descriptivos de documentos en general y los elementos de contenido en particular. El objeto de aprendizaje, como

20 Ver: Prototipo de patrimonio público de recursos educativos basados en una red institucional y un repositorio distribuido de objetos de aprendizaje. Participantes: Ma. Elena Chan Núñez. Universidad de Guadalajara, Jorge Martínez Peniche. DGSCA-UNAM, Rafael Morales Gamboa. Instituto de Investigaciones Eléctricas, Víctor G. Sánchez Arias. Laboratorio Nacional de Informática Avanzada A.C. Reporte de Investigación, 2004. (documento interno de trabajo) p. 14 
fenómeno emergente, se encuentra en constante evolución debido a los avances psicopedagógicos y a los desarrollos constantes de las tecnologías involucradas. Así, el OA se genera, adapta y modifica de acuerdo con las necesidades o imposiciones de la innovación tecnológica, lo cual ha motivado que sea visto como objeto único que presenta nuevas realidades de uso y aplicación en el aprendizaje en línea del siglo XXI.

\section{INVESTIGACIÓN EMERGENTE Y RELEVANTE} RELACIONADA CON OBJETOS DE APRENDIZAJE

Se puede afirmar que los estándares educativos propuestos principalmente por la innovación tecnológica se generalizan en los inicios del presente siglo, a partir de ello, diversos grupos de profesionistas se han interesado en estudiar las posibilidades y alcances de tales estándares para la del siglo XXI. En la actualidad, cobra mayor interés el estudio de estándares y tecnologías emergentes por lo que se han generado investigaciones de carácter multidisciplinario con el propósito de incidir con mayor profundidad en el estudio teórico y aplicado de los estándares educativos.

Así, el programa MERLOT ${ }^{21}$ se concibe como un sistema libre y abierto para ligar colecciones en línea de utilidad para los actores del aprendizaje, principalmente en el nivel superior. A partir de 1999 el trabajo cooperativo ha integrado a las siguientes instituciones: University of Georgia, Oklahoma State Regeants for Higher Education, University of North Carolina System, y California State University System. Dichas universidades, reconocen los beneficios de la cooperación para incrementar las colecciones digitales de MERLOT. Por ello, han contribuido con $\$ 20,000$ dólares para desarrollar el software MERLOT y con más de \$30,000 dólares para apoyar otros requerimientos del proyecto. En el 2006, MERLOT planea continuar con su programa cooperativo, explorar varios modelos de negocios y desarrollar un plan sustentable que sirva a los requerimientos tecnológicos académicos de los actores del aprendizaje de diversas instituciones.

Por su parte el proyecto CAREO (Campus Alberta Repository of Educational Objects $)^{22}$ se define como prototipo de repositorios de objetos educativos y contempla nuevas teorías y propuestas relacionadas como apoyo al desarrollo de objetos de aprendizaje. Participan en este proyecto las universidades de Alberta, Calgary y Athabasca, así como el Broadband Enabled Lifelong

21 MERLOT. [en línea] http://www.merlot.org/ [consultada: 31/05/05]

22 CAREO. Campus Alberta Repository of Educational Objects [en línea] 
Learnig Environment (BELL) y Canadian Network for the Advancement of Research in Industry and Education (CNARIE).

Asimismo el proyecto LOR-VCILY ${ }^{23}$ (Learning Objects Repository) realizado por la University of Mauritius ha desarrollado una biblioteca digital de objetos de aprendizaje. Su principal interés consiste en que investigadores y tutores de la Universidad tengan la posibilidad de agregar a la biblioteca sus objetos de aprendizaje, las pedagogías relacionadas con dichos objetos, y sus comentarios y referencias a ligas que contengan objetos de aprendizaje.

Prototipo de patrimonio público de recursos educativos basado en una red institucional y un repositorio distribuido de objetos de aprendizaje. Este proyecto realizado por la Universidad de Guadalajara (UDG), la Universidad Nacional Autónoma de México (UNAM), el Instituto de Investigaciones Eléctricas (IIE), y el Laboratorio Nacional de Informática Avanzada A.C. (LANIA), se plantea como objetivos principales los siguientes:

- La creación de un almacén de recursos didácticos que puedan usarse y reutilizarse por la comunidad CUDI. [Comisión de Universidades para el Desarrollo de Internet].

- La definición de un modelo pedagógico básico para procesos de enseñanza y aprendizaje basado en la existencia de un patrimonio común de recursos educativos organizados como objetos de aprendizaje y redes de objetos de aprendizaje.

- La especificación e implementación de la plataforma y estándares para el desarrollo del prototipo del patrimonio común de objetos de aprendizaje, que se derivan del modelo pedagógico seleccionado.

- El diseño e implementación del prototipo de patrimonio común de objetos de aprendizaje, que pueda servir como base para el desarrollo posterior del patrimonio de la comunidad CUDI.

- La difusión del prototipo en la comunidad CUDI como base para la creación de un patrimonio común de objetos de aprendizaje. ${ }^{24}$

Algunos de los logros del grupo se relacionan con la certeza de utilizar las especificaciones de Instructional Management System (IMS); y las funcionalidades básicas de los repositorios fueron definidas como alta, búsqueda $y$ despliegue de objetos y sus contenidos. La estructura lógica del patrimonio se apoya en una base de unidades de aprendizaje codificadas con XML de acuerdo con IMS. El sistema de recuperación de objetos de aprendizaje

23 LOR-VCILTY University of Mauritius. MERLOT. [en línea]

http://www.vcampus.uom.ac.mu/lor/ [consultada:31/05/05]

24 Op. cit. Prototipo de patrimonio público de recursos educativos basados en una red institucional y un repositorio distribuido de objetos de aprendizaje. Participantes: Ma. Elena Chan Núñez. [y otros] p.3 
se base en documentos estructurados con XML y en el lenguaje de consulta Xquery. También se adoptaron los estándares definidos por la tecnología de servicios web que basa las interacciones entre sitios heterogéneos en un protocolo de intercambio de datos estándar, denominado SOAP. ${ }^{25}$

Es importante señalar que dicha investigación tomó en consideración especificaciones y estándares internacionales, como las de IMS, el IEEE y las de ISO/IEC, sin embargo, el grupo de trabajo concluyó que para la definición de redes de repositorios, estos estándares son aún muy generales, y se percataron de que los existentes no están totalmente definidos o no son todavía estables. Por lo tanto se requiere investigar desde diversos frentes lo relacionado a los estándares educativos y su repercusión en el apoyo a la enseñanza de las disciplinas en escenarios virtuales. Sin duda los resultados de la investigación relacionada con la creación de un modelo y un prototipo de patrimonio abierto de objetos de aprendizaje, generará resultados de mucho valor para el desarrollo de objetos de aprendizaje y su utilidad en la educación del presente siglo.

Biblioteca Digital de Materiales didácticos de la UNAM. ${ }^{26}$ La Universidad Nacional Autónoma de México (UNAM) cuenta con académicos altamente calificados y con recursos tecnológicos de apoyo para desarrollar material didáctico original y adecuado para la población estudiantil en las diversas modalidades educativas. Asimismo posee valiosas colecciones de materiales didácticos, aunque no se cuenta todavía con herramientas que garanticen la organización sistematizada de esas colecciones, lo cual dificulta su consulta.

Una forma de resolver esta carencia surgió como parte del trabajo colegiado y multidisciplinario desarrollado por la Comisión de Materiales Didácticos (COMADI) generada en el seno del Consejo Asesor de la Coordinación de Universidad Abierta y Educación a Distancia (CUAED). La COMADI tiene como propósito diseñar y desarrollar la Biblioteca Digital de Materiales Didácticos de la UNAM (BIDI-MADI-UNAM). También se pretende escalar, a mediano plazo, hacia la incorporación de objetos de aprendizaje.

Los miembros de la COMADI asumen que las tecnologías de información y comunicación han producido cambios significativos en las sociedades con respecto a las formas de comunicación que existen en amplios sectores sociales, y a la posibilidad de acceder a la información vía redes de teleproceso. En cuanto a la educación, en todos sus niveles, la convergencia de las tecnologías adquiere cada vez mayor importancia dada la posibilidad de establecer diálogos remotos entre individuos y grupos, la facilidad para transmitir

25 Cf. Ibidem, p.13.

26 Información basada en: "Biblioteca Digital de materiales didácticos de la UNAM". Ponencia elaborada por la COMADI y presentada en Virtual Educa 2005. 
información y conocimiento que actúe como herramienta del aprendizaje, la simplificación para efectuar evaluaciones académicas, y la generación de espacios virtuales.

La incorporación de tecnologías en procesos informativos para la educación abierta y a distancia obliga a considerar su pertinencia, así como la creación de grupos multidisciplinarios que aborden la discusión acerca de las novedosas formas de vinculación surgidas entre la generación acelerada de información y el desarrollo de materiales didácticos y de objetos de aprendizaje.

La convergencia de métodos de aprendizaje con las tecnologías de información y comunicación presenta ventajas considerables para administrar y organizar estratégicamente materiales didácticos y objetos de aprendizaje, y para individualizar servicios informativos y acceder a los contenidos educativos utilizando múltiples llaves de recuperación que amplían las posibilidades de uso en relación con la demanda real de los usuarios.

\section{Perspectivas de los objetos de APREndizaje EN EL CAMPO DE LA BIBLIOTECOLOGÍA}

Los objetos de aprendizaje son inherentes a cualquier disciplina, sin embargo, hasta nuestros días en el campo de la bibliotecología resultan un fenómeno de investigación escasamente estudiado debido a su reciente aparición y a la poca investigación de frontera que se realiza en este tema. Sin embargo debemos incidir en investigaciones que expliquen la aparición y el desarrollo de la propuesta relacionada con objetos de aprendizaje y teorizar con relación a sus repercusiones a corto y mediano plazos para la enseñanza de la bibliotecología.

Esta investigación debe contemplar entre otras dimensiones de estudio las siguientes: el surgimiento de la propuesta de objetos de aprendizaje, los componentes que caracterizan a éstos, los marcos teóricos que pueden incidir en su desarrollo, los medios portadores de objetos de aprendizaje, los estándares educativos propuestos para su desarrollo, y la reutilización y transmisión, vía redes de teleproceso y estándares de metadatos orientados a la organización de objetos de aprendizaje. Algunos de estos asuntos se muestran en las imágenes siguientes: 


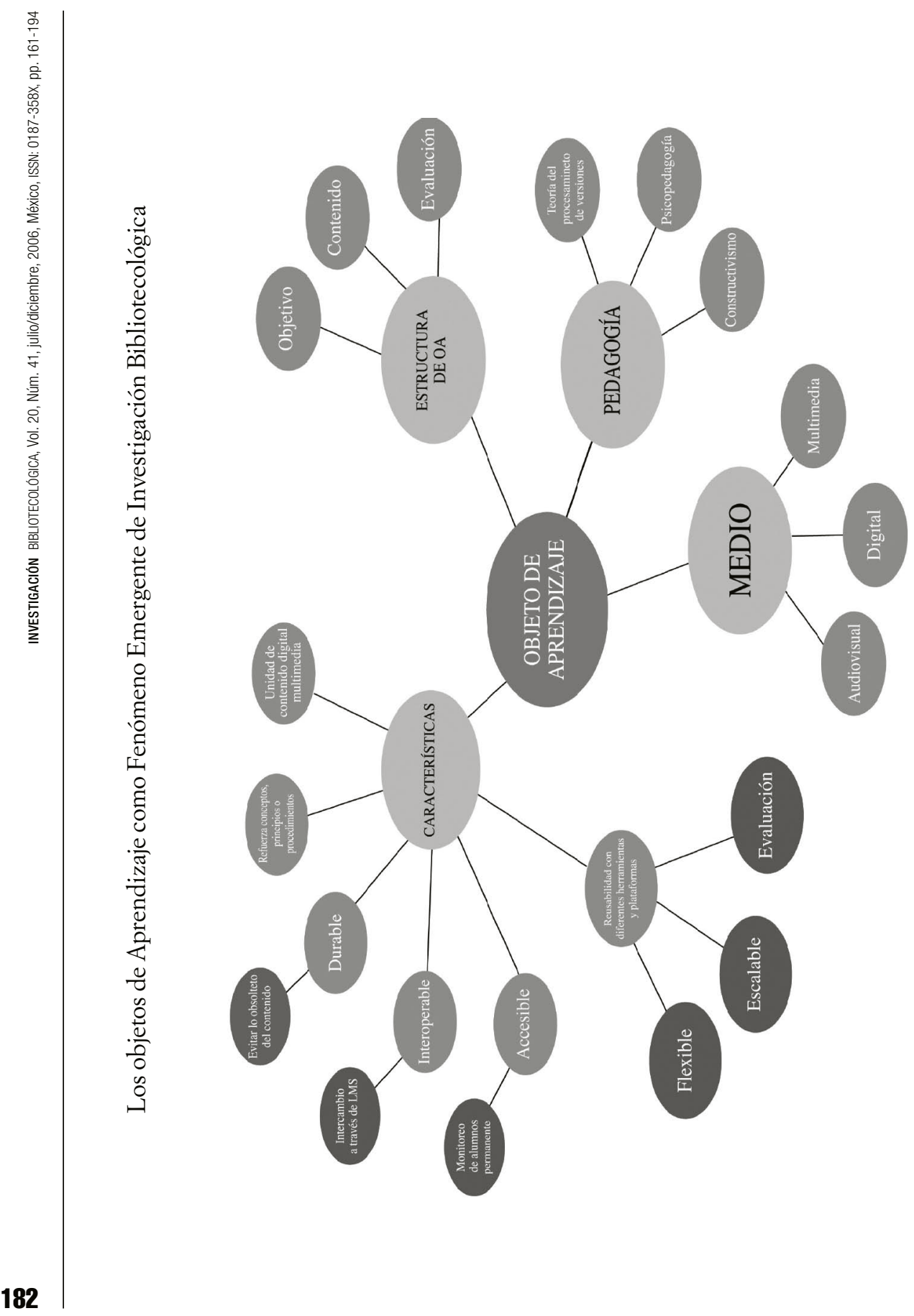




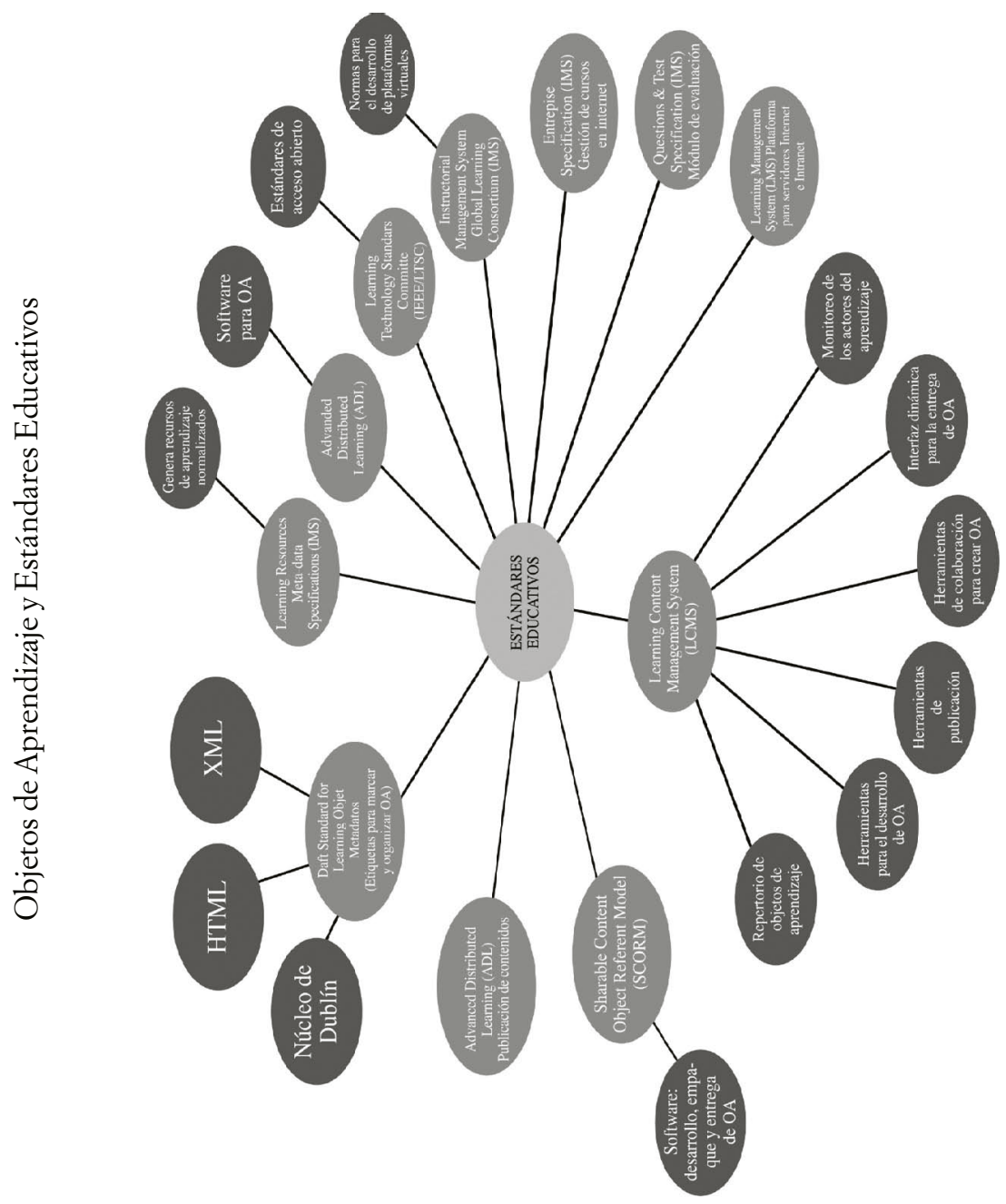


Es obvio que los fenómenos generados por la innovación tecnológica le plantean nuevos retos a la bibliotecología al haber transformado los modelos y procesos educativo, y modificando las formas de comunicación académica y las formas de interacción y comunicación entre los diversos actores del proceso educativo. También es claro que las redes de telecomunicación facilitan cada vez más el acceso a la información en un entorno global, pues su alta velocidad reduce los límites de las fronteras, y sus modificaciones en el espaciotiempo facilitan la recuperación de información requerida en los complejos procesos de enseñanza-aprendizaje.

La generación de objetos de aprendizaje orientados a la enseñanza de la bibliotecología requiere un aprendizaje innovador, la formación de asesores y tutores, y la preparación de autores de contenido. El aprendizaje virtual de fenómenos relacionados con la bibliotecología exige un docente experto en la materia que conozca los fundamentos del diseño instruccional y el perfil de los alumnos a distancia, y que sepa planeación curricular y pueda mantenerse en comunicación con los alumnos en línea. La interactividad y la navegación en red son fenómenos de gran interés para la bibliotecología por su novedad y los pocos avances que se han logrado en esto hasta nuestros días. Por lo tanto, los diseñadores de objetos de aprendizaje deberán analizar detenidamente los problemas que siguen causando estos asuntos en los procesos de aprendizaje vía redes de teleproceso.

Al mismo tiempo, los contenidos de los objetos de aprendizaje deberán explicar que los fenómenos bibliotecológicos se presentan en escenarios sociales específicos, y que su evolución ha generado instituciones sociales para la organización, preservación y difusión de la cultura. Así, la enseñanza y la investigación bibliotecológica referida al aprendizaje virtual en este campo debe explicar que una formación adecuada del bibliotecólogo requiere hábitos de aprendizaje individuales y colectivos orientados hacia un conocimiento teórico equilibrado con el conocimiento aplicado. Lo anterior implica esencialmente un dominio del conocimiento de los fenómenos bibliotecológicos, aspecto que debe plasmarse en el discurso de los objetos de aprendizaje que se desarrollen para la enseñanza. Con ello se buscaría que el estudiante en escenarios virtuales se oriente hacia la adquisición de un conocimiento significativo y reafirme su propio valor en diversos aspectos de su vida profesional.

Es necesario que los autores de contenido tomen en consideración que el alumno habrá de aprender a identificar los fenómenos bibliotecológicos y a apropiarse de conocimientos relevantes generados en otras disciplinas que lo ayuden a comprender y explicar los fenómenos propios de la bibliotecología. El aprendizaje virtual de esta disciplina implica buscar la formación de un alumno a partir de aglutinar los conocimientos disponibles con la finalidad 
de que adquiera conocimientos que le faciliten ejercer su profesión en un mercado de trabajo sujeto a constantes cambios. En este sentido, el aprendizaje sobre bibliotecología requiere de marcos referenciales que faciliten la comprensión de su génesis y desarrollo con el propósito de identificar los fenómenos y problemas que deben ser estudiados por la investigación y la enseñanza bibliotecológica.

Los objetos de aprendizaje habrán de explicar en sus contenidos, que el fenómeno de la globalización ha penetrado en las sociedades con la intención de eliminar barreras de comunicación para facilitar los flujos de la información a través de la tecnología digital, la informática y las telecomunicaciones. En consecuencia, el estudio de la globalización y su repercusión teórica y aplicada en la bibliotecología, implican a su vez, evaluar, conocer y manejar las herramientas tecnológicas que realmente apoyan y le garantizan al estudiante la adquisición de conocimiento significativos referidos a la disciplina.

Plantearse nuevos fenómenos de estudio que se reflejen en el contenido de objetos de aprendizaje, implica incidir en la formación de un profesional que identifique, detecte, organice, cree y difunda, a través de tecnologías de vanguardia, información de carácter especializado en áreas estratégicas para el desarrollo local, nacional y regional de determinada nación. En este contexto, se percibe que la sociedad actual crea nuevas demandas referidas a los servicios de información, los cuales pueden incluir factores estratégicos que, en muchos casos, pueden incidir en la toma de decisiones de diversos sujetos sociales.

Así, por ejemplo, al desarrollar objetos de aprendizaje que aborden la enseñanza de la normalización documental, se debe explicar que los estándares de catalogación y clasificación orientados al control bibliográfico de documentos digitales, deberán considerar que éstos contienen un conjunto de elementos de catalogación comunes a cualquier otra presentación documental. Sin embargo, "[...] tienen otra información específica relacionada con su naturaleza, como son: el entorno operativo, las formas de acceso y las condiciones de utilización". ${ }^{27}$

En los inicios del siglo XXI, el debate actual entre bibliotecarios, documentalistas e informáticos impide predecir el futuro de los diversos instrumentos normativos. Sin embargo lo que es evidente es la necesidad de enseñar y lo que es la normalización para poder sistematizar los documentos digitales (entre los que se pueden incluir los objetos de aprendizaje). Tales instrumentos normativos son importantes porque: 
- Son una manifestación más de la cultura y del desarrollo de las naciones por lo que deben ser conservadas y puestas a disposición de la sociedad. Su recuperación y localización se ven facilitadas mediante descripciones bibliográficas que las identifiquen y enlaces hipertextuales que permitan su acceso y consulta.

- El registro bibliográfico redactado a partir de un ejemplar recibido directamente del editor por medio del depósito legal, es una medida de garantía de los derechos de la propiedad intelectual y un procedimiento que autentifica las características de la edición original". ${ }^{28}$

La enseñanza virtual sobre la organización de documentos digitales en línea (entre los que se pueden encontrar los objetos de aprendizaje) es también necesaria debido a las siguientes razones:

- Los índices existentes en la red (Internet) son inadecuados; contienen insuficientes datos descriptivos y muestran falta de normalización de los datos y su presentación a menudo resulta de poco valor para los usuarios, y no está totalmente claro que se mantengan durante un periodo largo de tiempo.

- La naturaleza dinámica de los mecanismos de la red significa que no se guarda un registro de los recursos que se retiran de ésta.

- Los cambios frecuentes de los documentos y de las localizaciones conducen a cuestiones relacionadas con la autenticidad que sólo se pueden resolver mediante un control bibliográfico formal.

- El control bibliográfico puede ayudar a proteger a los autores contra la piratería en un entorno donde la información puede ser copiada y manipulada con facilidad.

- El depósito y el control bibliográfico pueden contribuir a realzar el estatus de las publicaciones electrónicas.

- La colección de depósito tiene que ser catalogada en cualquier caso para asegurar que las publicaciones puedan ser localizadas por las generaciones futuras. ${ }^{29}$

En este contexto, la orientación de las nuevas propuestas de normas se proponen tener un alcance internacional en materia de control bibliográfico y facilitar la integración de algunos sistemas de información: bases de datos bibliográficos, catálogos públicos en línea, sistemas de metadatos y bibliotecas digitales. La organización de objetos de aprendizaje que incluyan datos psicopedagógicos es un asunto que debe ser resuelto por la investigación y la enseñanza en bibliotecología, pues sus características y datos propios los hacen diferentes a los tipos de documentos conocidos hasta nuestros días.

28 Ibidem, p. 240

29 J.S. Mackenzie Owen y J. V. D. Walle. Citado por Ernesto García Camero y Luis Ángel García Melero. La biblioteca digital. Madrid: Arco/Libros, 2001. p. 240 
Así, los autores de objetos de aprendizaje deben tener en mente que la atención a estos asuntos requiere de un profesionista en bibliotecología que tenga capacidad para identificar y caracterizar escenarios culturales, sociales y económicos en los que sea factible aplicar tecnologías de información y comunicación para realizar una adecuada gestión de las estas últimas para diseñar sistemas de información adecuados a las instituciones y a los sujetos que demandan los servicios de información.

La investigación relacionada con la educación virtual en bibliotecología, que se puede encontrar la relacionada con objetos de aprendizaje, debe prever que los contenidos y las estrategias didácticas que se utilicen, le ofrezcan al alumno una preparación profesional con niveles óptimos de conocimiento bibliotecológico y tecnológico acorde con los diversos escenarios sociales. $\mathrm{Al}$ mismo tiempo se debe asegurar que el alumno adquiera conocimiento y destrezas para diseñar, organizar y proveer de servicios de información dirigidos a diversos entornos sociales, además de considerar, entre otros fenómenos, lo global, la sociedad de la información y la sociedad del conocimiento. Tales fenómenos indican la necesidad que tiene la bibliotecología de incidir en ambientes sociales cooperativos integrados.

En el presente milenio se vislumbra con mayor certeza que la convergencia tecnológica se orienta cada vez más hacia la generación de plataformas en entornos digitales, sistemas de información en línea y contenidos de aprendizaje en diversidad de formatos. En consecuencia la educación virtual del siglo XXI se encuentra en la búsqueda permanente de generación de materiales y objetos de aprendizaje de alta calidad, la utilización apropiada de tecnologías de vanguardia en propuestas educativas virtuales y a la innovación de los aprendizajes sin descuidar las dimensiones de reflexión, investigación y colaboración académica institucional.

\section{Conclusiones}

En la educación virtual, el autor de contenido debe tener en mente que las tecnologías presentan alternativas competitivas en la comunicación, la entrega de materiales didácticos y la recuperación de información complementaria a los aprendizajes. En este sentido, cabe resaltar que la estructura informativa de la educación en línea se basa en el hipertexto. Así, las tecnologías de red ofrecen diversas posibilidades de comunicación con el alumno, controles académicos versátiles, desarrollo de materiales didácticos, y objetos de aprendizaje basados en estructuras de hipertexto, multimedia, videoconferencia, correo electrónico, bibliotecas digitales y sistemas de metadatos. Esta 
educación acentúa la generación de flujos de información digital que le dan apoyo complementario a la educación en línea. En este contexto la comunicación educativa, la interacción, el diálogo, el modelo docente de aprendizaje, el material didáctico, los objetos de aprendizaje, la asesoría y la tutoría en línea, constituyen la base sobre la cual se sustenta el éxito o fracaso de cualquier propuesta educativa a distancia.

La innovación tecnológica relacionada con objetos de aprendizaje ha requerido la generación de un conjunto de estándares educativos para que éstos puedan ser desarrollados, organizados, recuperados y transmitidos vía redes de teleproceso y reutilizados por los actores del aprendizaje virtual. El hecho de que tales estándares educativos no incluyan de manera específica aspectos psicopedagógicos, más que una debilidad puede verse como una oportunidad, para los pedagogos y los autores de contenido de proponer o generar teorías que produzcan aprendizaje significativo en escenarios virtuales, en beneficio de las disciplinas y de los alumnos a distancia.

El discurso que tiene el objeto de aprendizaje lo genera el autor de contenido y tiene mayor uso cuando se encuentra en línea. El OA es una herramienta que estructura contenidos flexibles, manipulables, que es reutilizable y que tiene ligas con otros objetos, y es también trasferible a través de Internet; su estructura puede contener ligas en diversos sentidos y los elementos que lo constituyen lo convierten en un objeto inacabado, por lo que puede ser reescrito para adecuarse a los objetivos de la propuesta educativa específica.

Sistematizar el control y la recuperación de objetos de aprendizaje representa una oportunidad y un reto para la bibliotecología y la enfrenta a un fenómeno novedoso que exige métodos de organización y recuperación complejos. En consecuencia habrá que buscar que a través de ellos los diferentes elementos bibliográficos, de contenido y psicopedagógicos, puedan ser ligados a los datos del propio OA o a otros objetos disponibles en distintas bibliotecas digitales, sistemas de metadatos o repositorios de objetos de aprendizaje. Esta posibilidad debe potenciar su uso y beneficiar a los actores del proceso de enseñanza a distancia gracias a los vínculos de referencias, avanzar de un recurso informativo a otro, navegar por los datos bibliográficos y los contenidos del objeto y obtener información con base en intereses académicos específicos. Al mismo tiempo habrá que tomar en consideración métodos de organización y mecanismos tecnológicos complementarios para que el OA pueda ser reutilizado y que posteriormente, docentes y alumnos generen nuevas versiones de objetos de aprendizaje de utilidad para el aprendizaje a distancia.

Las propuestas de formación docente para la educación virtual en bibliotecología son, hasta el momento, escasas e incompletas, por ello resulta oportuno 
proponer el diseño y desarrollo de programas de esta naturaleza en los que participen diversas instituciones educativas con el fin de compartir expertos, experiencias y tecnologías. Conviene tomar en cuenta que la formación en línea replantea las nociones de comunicación virtual, interactividad, conectividad en línea, flujos de información y de conocimiento, y costos. La distancia redefine al individuo respecto al espacio y al tiempo e implica un desfase temporal entre los actores del aprendizaje.

La educación virtual, la innovación tecnológica, el desarrollo de objetos de aprendizaje y el acceso vía Internet a recursos informativos digitales, nos obligan a repensar nuevas formas de enseñanza-aprendizaje y lleva a los docentes a revalorar los sustentos pedagógicos de la enseñanza en bibliotecología. Al mismo tiempo las oportunidades que otorga la formación en línea, implican que la investigación bibliotecológica reflexione y proponga nuevas formas de sustentar y comunicar los aprendizajes en escenarios virtuales y nuevas funciones que deben cumplir los docentes de dicha disciplina.

Es necesario que la bibliotecología analice la orientación actual de los modelos educativos e intente que los docentes transiten hacia la educación presencial, abierta y virtual sin perder de vista la calidad educativa y la preparación que afronta la competitividad que exige la internacionalización de la educación superior y la movilidad profesional. Lo anterior, requiere considerar, entre otros aspectos, el desarrollo de la disciplina y la cooperación en un mundo globalizado.

\section{BiBLIOGRAFÍA}

Barrón Soto, Héctor S. La educación en Línea y el texto didáctico. México: UnAM, Coordinación de Universidad Abierta y Educación a Distancia: Facultad de Filosofía y Letras, 2004. 100p.

Cabrero A. Julio. "Nuevas Tecnologías, comunicación y educación”. en EDUTEC. Revista electrónica de tecnología educativa, núm.1, feb. 1996. [en línea] www.http://uib.es/depart/gte/revelec1.html [consultada: 20/09/04]

Careo. Campus Alberta Repository of Educational Objects [en línea] http://www.careo.org/ [consultada: 31/05/05]

Cardona Ossa, Guillermo. "Tendencias Educativas para el Siglo XXI Educación Virtual”, en Online y @learning elementos para la discusión. Edutec. [en línea]

http://edutec.rediris.es/Revelec2/revelec15/cardona.pdf [consultado: 09/03/05] 
Castellanos Coutiño, Carlos Alberto. "Panorama general de los sistemas de educación a distancia", en Primer Congreso Virtual Latinoamericano de educación a distancia. [en línea] LatinEduca2004. com [consultada: 10/03/2005].

Contreras M. Rita. "Reflexiones en torno al uso de la tecnología de la información en el terreno educativo", en Soluciones Avanzadas: tecnologías de información y estrategias de negocios, jun. 1997, vol. 5, no. 46, pp. 10-15

“Contenidos e-learnig. En e-learnig América Latina”, en la Revista Digital de e-Learnig en América Latina. Año1, número 8, noviembre de 2004. [en línea] http://www.elearnigamericalatina.com/edicion/noviembre/index.php [consultada: 03/11/05]

Cornella, Alfonso. "e-Learning: de la formación de los empleados al conocimiento en toda la cadena de valor". en El Profesional de la Información, Vol. 11, Núm. 1, enero-febrero 2002. pp. 65-68.

Contreras M. Rita. "Reflexiones en torno al uso de la tecnología de la información en el terreno educativo", en Soluciones Avanzadas: tecnologías de información y estrategias de negocios, jun. 1997, vol. 5, no. 46, pp. 10-15

Crovi Druetta, Delia. "Virtudes de la virtualidad: algunas reflexiones desde la educación”, en Tecnología y Comunicación Educativa 1999 , vol. 13, no. 29, p.75-86

Diccionario de las ciencias de la educación. México: Santillana, 1995. $1431 \mathrm{p}$.

Draft standard for learning object metadata. Sponsored by the Learning technology Standards Committee Piscataway, N. J. : IEEE Standards

Department, 2002 [en línea] http://ltsc.ieee.org/wg12/files/LOM_1484_12_1_v1_Final_Draft.pdf [consultada: 14/05/05]

Enciclopedia de pedagogía. España: Espasa, 2002. p. 1115.

The Dublin Core Initiative. [en línea] http://purl.oclc.org/metadata/Dublin core/ [consultada: 16/02/05]

E-learning: soluciones de e-learning. Formación a Distancia [en línea]. <http://e-learning.bankhacker.com/ > [consultada: 08/05/04]

Institute of Electronic and Electronics Engineers, Inc. IEEE 1484.12.12002 Draft Standard for Learnig Objet Metadata. New York: IEEE, 2002 44p..

Iriarte Navarro, Leonel [et al.]. "Generación de una biblioteca de objetos de aprendizaje (LO) a partir de contenidos preexistentes", en Revista de Educación a Distancia, no. 2, 2005 [ en línea ] http://www.um.es/ead/M2 [consultado el 14 de abril 2005]

Laorden, Cristina, Elena García y Salvador Sánchez. Integrando descripciones de habilidades cognitivas en los metadatos de los objetos de aprendizaje estandarizados, 2005 [ en línea ]

http://spedece.uah.es/papers/Laorden_Final.pdf. [14/04/05] 
Lever-Duffy, Judy. Teaching and learning with technology / Judy Lever-Duffy, Jean B. McDonald, Al P. Mizell. - Boston: Pearson Education, Inc., c2003. xxi, 439 p.

Lor-Vcilty University of Mauritius. MERLOT. [en línea] http://www.vcampus.uom.ac.mu/lor/ [consultada:31/05/05]

Loyo Varela, C. y V.G. Sánchez. "La telemática y la educación a distancia [en línea]", en Soluciones Avanzadas, ago. 1995, vol. 4, no. 24 $<$ http://www.lania.mx/nivel2/divulgacion.html>

Martínez Romero, Rina María, Roberto Garduño Vera [y otros]. "Modelo psicopedagógico para el diseño y la evaluación de materiales didácticos en la Educación a Distancia”, en Encuentro Internacional de Educación Superior UNAM, Virtual Educa 2005, del 20 al 24 de Junio de 2005, Palacio de Minería, Ciudad de México. [México: CUAED, UNAM. 2005, Memorias en CD-ROM]

Merlot. [en línea] http://www.merlot.org/ [consultada:31/05/05]

Pontificia Universidad Javieriana. Aprender a distancia. [en línea] http://www.javieriana.edu.co/cua/aprender.htm [consutada: 04/10/04]

Prototipo de patrimonio público de recursos educativos basados en una red institucional y un repositorio distribuido de objetos de aprendizaje. Participantes: Ma. Elena Chan Núñez. Universidad de Guadalajara, Jorge Martínez Peniche. DGSCA-UnAm, Rafael Morales Gamboa. Instituto de Investigaciones Eléctricas, Víctor G. Sánchez Arias. Laboratorio Nacional de Informática Avanzada A.C. Reporte de Investigación, 2004. 38p. (documento interno de trabajo)

Reunión de la Comisión Académica de Objetos de Aprendizaje. (Guadalajara, Jal. 4 de julio 2002). [en línea] $<$ http://www.cudi.org/ob_ap.html> [Consultada:10/10/03]

Romero, Daniel y otros]. "Gateway para el reciclaje de sistemas elearning que no cumplen con SCORM”, en Primer Congreso Virtual Latinoamericano de Educación a Distancia 2004. [en línea] http://www.ateneonline.net/datos/65_03_Romero_Daniel.pdf [Consultada: 30/03/05]

Rovira, Cristofol. La orientación a objetos en el diseño de hipertextos para la enseñanza - aprendizaje, 1999 [en línea] http://www.ucm.es/info/multidoc/multidoc/revista/num8/rovira.html [consultado: 02/03/05] , "Hypertext representation for education and learning", en Interactive Educational Multimedia. núm. 5, 2002

Subotovsky, Santiago. Consideraciones básicas para su proyecto de desarrollo de contenidos, 2004 [ en línea ] http://www.elearningamericalatina.com/edicion/noviembre1_ 2004/na_1.php [consultado el 14 de abril 2005] 
Tele-learning: the challenge for the third millennium / Edited by Don Passey, Mike Kendall. Norwell, Massachusett: Kluwer Academic Publishers, 2002. xxiii, 372 p.

Urdan, T. y C. Weggan. Citados por Carlos Marcelo [et al.] Formando teleformadores: diseño y desarrollo de un curso online utilizando WebcT. [en línea]

$<$ http://s.es/idea/mie/pub/marcelo/Formando\%20Teleformado res.pdf $>$ [consultada:09/08/05]

Zapata Ros, Miguel. "Secuencia de contenido y objetos de aprendizaje", en RED. Revista de Educación a Distancia, no. 2, 2005 [ en línea ] http://www.um.es/ead/red/M2//zapata47.pdf [consultado el 14 de abril 2005]

\section{ANEX0 1:}

Estándares educativos y objetos de aprendizaje: direcciones electrónicas relevantes Learning technology standards ${ }^{30}$ [estándares tecnológicos para el aprendizaje]

IEEE Standards. Contempla la sintaxis y la semántica de los objetos de aprendizaje utilizando metadatos

- $\quad$ IEEE Standard for Learning Object Metadata (IEEE 1484.12.1:2002 LOM) http://ltsc.ieee.org/wg12/

- $\quad$ IEEE Draft Standard for XML Binding for Learning Object Metadata Data Model (IEEE 1484.12.3 LOM XML) http://ltsc.ieee.org/wg12/

- $\quad$ IEEE Draft Standard for Data Model for Content Object Communication (IEEE 1484.11.1 CMI DM) http://ltsc.ieee.org/wg11/

- IEEE Standard ECMAScript API for Content to Runtime Services Communication (IEEE1484.11.2:2003 CMI API) http://ltsc.ieee.org/wg11/

IMS Specifications. Contiene las especificaciones de software para el desarrollo de contenido y repositorios de objetos de aprendizaje

- $\quad$ IMS Content Packaging Specification (IMS CP 1.1.3)

http://www.imsglobal.org/content/packaging/

- $\quad$ IMS Digital Repositories (IMS DRI 1.0)

http://www.imsglobal.org/digitalrepositories/

- $\quad$ IMS Enterprise Specification (IMS ENT 1.1)

http://www.imsglobal.org/enterprise/

- $\quad$ IMS Learning Design Specification (IMS LD 1.0)

http://www.imsglobal.org/learningdesign/

- IMS Learner Information Package Specification (IMS LIP 1.0)

http://www.imsglobal.org/profiles/ 
- $\quad$ IMS Learning Resource Metadata Specification (IMS MD 1.2.1)

http://www.imsglobal.org/metadata/

- $\quad$ IMS Question and Test Interoperability Specification (IMS QTI 1.2.1)

http://www.imsglobal.org/question/

- $\quad$ IMS Reusable Definition of Competency or Educational Objective Specification (IMS RDCEO 1.0) http://www.imsglobal.org/competencies/

- IMS Simple Sequencing Specification (IMS SS 1.0)

http://www.imsglobal.org/simplesequencing/

- IMS Vocabulary Definition Exchange Specification (IMS VDEX 1.0)

http://www.imsglobal.org/vdex/

AICC Specifications. Agrupa especificaciones para tipos de documentos digitales

- $\quad$ AICC CMI Guidelines for Interoperability (AICC CMI001 V3.5)

http://www.aicc.org/pages/down-docs-index.htm

SCORM Resources. Contempla epecificaciones para el desarrollo de software, el empaquetado y la entrega de objetos de aprendizaje

ADL SCORM Resources

- $\quad$ SCORM 1.2 (SCORM 1.2)

http://www.adlnet.org/index.cfm?fuseaction=scormdown

- $\quad$ SCORM 1.3 Draft (SCORM 1.3)

http://www.adlnet.org/index.cfm?fuseaction=scormdown

- $\quad$ The SCORM Implementation Guide: A Step-by-Step Approach (SCORM 1.2)

http://www.adlnet.org/index.cfm?fuseaction=rcdetails\&libid $=493 \& \mathrm{cfid}=19034 \& \mathrm{cftoken}=49$

846145

- $\quad$ SCORM Sample Run Time Environment (SCORM 1.2.1 RTE)

http://www.adlnet.org/index.cfm?fuseaction=scormdown

- $\quad$ SCORM Sample Content Packages (SCORM 1.2)

http://www.adlnet.org/index.cfm?fuseaction=scormdown

- $\quad$ SCORM Conformance Test Suite (SCORM 1.2.3)

http://www.adlnet.org/index.cfm?fuseaction=scormdown

Content Development Resources. Son especificaciones para el desarrollo de objetos de aprendizaje

- $\quad$ The SCORM Implementation Guide: A Step-by-Step Approach (SCORM 1.2)

http://www.adlnet.org/index.cfm?fuseaction=rcdetails\&libid $=493 \&$ cfid $=19034 \&$ cttoken $=49$

846145

- $\quad$ CanCore Learning Object Metadata Application Profile Guidelines (CanCore)

http://www.cancore.org/documents.html

- $\quad$ IMS Guidelines for Developing Accessible Learning Applications

http://www.imsglobal.org/accessibility/

- Dr. Tom's Guide for Metadata (Tom Wason)

http://wason.home.mindspring.com/TDW/Papers.htm

- $\quad$ IMS Implementation Handbooks (IMS)

http://www.imsglobal.org/implementationhandbook/

Tools. Herramientas complementarias para apoyar el desarrollo de objetos de aprendizaje

- $\quad$ SCORM Runtime Wrapper Extension for Dreamweaver MX (Macromedia)

http://www.macromedia.com/resources/elearning/ extensions/dw_ud/scorm.html 
- $\quad$ Microsoft LRN Toolkit (LRN 3.0)

http://www.microsoft.com/elearn/support.asp

- $\quad$ SCORM Detective Tool (SABA)

http://www.learningestore.com/sabapartners?ssp=\%2Fcatalog\%2Fproducts_search_detail. saba\&id $=$ prdct000000000033852 $\&$ price $=0$

\section{ANEX0 2:}

\section{Organizaciones involucradas con la educación en línea y los objetos de aprendizaje}

- $\quad$ ADL (Advanced Distributed Learning Initiative: US)

http://www.adlnet.org/

- $\quad$ ALIC (Advanced Learning Infrastructure Consortium: Japan)

http://www.alic.gr.jp/eng//

- $\quad$ EduSpecs (Industry Canada)

http://eduspecs.ic.gc.ca/index.html?iin.lang=en/

- $\quad$ MedBiquitous (Professional Medical Education)

http://www.medbiq.org/

- $\quad$ Asia e-Learning Network

http://www.asia-elearning.net/index.html

Organizaciones involucradas en el desarrollo de estándares educativos

- W3C (World Wide Web Consortium). http://www.w3.org/

- $\quad$ OASIS (Organization for the Advancement of Structured Information Standards).

http://www.oasis-open.org/

- $\quad$ WS-I (Web Services Interoperability Organization).

http://www.ws-i.org/

- $\quad$ DCMI (Dublin Core Metadata Inititiative).

http://dublincore.org/

- $\quad$ DOI (Digital Object Identifier).

http://www.doi.org/ 